\title{
IMPROVEMENT OF STORM SURGE SIMULATION UPON PARAMETERIZATIONS OF COUPLED AIR-SEA INTERACTIONS
}

\author{
Junichi Ninomiya ${ }^{1}$, Nobuhito Mori ${ }^{2}$, Tomohiro Yasuda ${ }^{2}$, Hajime Mase $^{2}$ and Naoto Kihara ${ }^{3}$ \\ Coupled atmosphere-ocean model has been developed in various organizations. Warner et al. developed \\ fully coupled model, so-called COAWST, using the atmosphere model WRF, the ocean model ROMS \\ and the wave model SWAN. Though there are several studies with coupled model, there is few research \\ on tropical cyclone event analyzing the changes in ocean current and water temperature in detail. In \\ this study, a series of numerical simulations was carried out targeting Typhoon Melor (2009), and it \\ is analyzed against to the meteorologic and oceanic field data at Tanabe bay, Wakayama Prefecture in \\ Japan. The results show that the wave energy dissipation by the wave model is effective in the change \\ of ocean current and the thermal feedback by the atmospheric model is effective in the change of water \\ temperature due to the typhoon passage. \\ Keywords: coupled model, storm surge, typhoon, ocean current, wind wave
}

\section{INTRODUCTION}

Various numerical models have been developed for several years due to the predictions of atmosphere, ocean and wave. Coupled atmospheric and ocean models have been developed due to improvement of computers the last decade. For example, Murakami et al. (2004) developed a coupling model consisted of atmosphere model MM5, ocean model CCM adopted multiple $\sigma$ coordinate and wave model SWAN. They computed storm surge in the future climate and there is a possibility of higher storm surge in future climate (Yoshino et al., 2009). On the other hand, Yamashita et al. (2007) simulated hindcasts of extreme typhoon that damaged by storm surge to the Seto Inland Sea using a coupling model of atmosphere model MM5, ocean model POM and wave model SWAN (Soo et al., 2009). Although the both atmospheric and ocean model has been developed, new type of flexible model is required to describe complex phenomena of air-sea interactions. Warner et al. (2008) developed a coupling model using the latest atmosphere model WRF, the ocean model ROMS and the wave model SWAN (so-called Coupled Ocean Atmosphere Wave Sediment Transport Modeling System: COAWST). The hindcasts of hurricane using COAWST was carried out and the improvement of calculation accuracy of sea surface temperature and wave height have been reported in detail (e.g. Warner et al., 2010). Both WRF and ROMS have been developed as a module based community model instead of MM5 and POM, and they have been implemented various physics to the models. It is expected to improve the accuracy of ocean and wave hindcasts due to the newly developed of the physics and numerical schemes by both models.

Although the hindcasts of hurricane using atmospheric-ocean coupled model have been done, few studies have validated and analyzed the changes of the water current and temperature in detail. This study conducted hindcasts of typhoon Melor in 2009 by several different configurations of the coupled model. The influence of coupling and uncoupling on ocean currents and temperature will be discussed for tropical cyclone landfall.

\section{FIELD OBSERVATION}

Field observations were carried out using the Tanabe-Nakashima oceanographic observation tower, Disaster Prevention Research Institute of Kyoto University, in Tanabe Bay at Wakayama prefecture. Measurement instruments were mounted on the tower from sea bottom to top. The atmospheric pressure, wind speed and direction, air temperature, specific humidity, air temperature, wave height, current velocity etc (Mori et al., 2010).

\footnotetext{
${ }^{1}$ Graduate School of Engineering, Kyoto University, Kyoto daigaku-Katsura, Nishikyo-ku, Kyoto 615-8530, JAPAN.

2 Disaster Prevention Research Institute, Kyoto University, Gokasho, Uji, Kyoto 611-0011, JAPAN.

${ }^{3}$ Central Research Institute of Electric Power Industry, 1646 Abiko, Abiko city, Chiba 270-1194, JAPAN.
} 


\section{COASTAL ENGINEERING 2012}

\section{MODEL AND SETUP}

\section{Numerical model}

COAWST is a model that is capable of tight coupling the atmosphere model WRF (Skamarock et al., 2005), the ocean model ROMS (Shchepetkin and McWilliams, 2005) and the wave model SWAN (Booij et al., 1999). Fig. 1 shows the diagram of COAWST with variables where U(V)wind is the wind data above $10 \mathrm{~m}$ from the ground, Patm the air pressure at sea surface, $\mathrm{RH}$ the relative humidity, Tair the air temperature, rain the precipitation, SWrad the shortwave radiation, LWrad the longwave radiation, SST the sea surface temperature, $\mathrm{u}(\mathrm{v})_{\mathrm{s}}$ the water current, $\eta$ the surface elevation, bath the bathymetry, Hwave the wave height, Lwave the wave length, Dwave the wave direction, Tsurf (bott) the surface (bottom) wave period, Qv percent of the wave breaking, Wdissip the wave energy dissipation, Ub the bottom orbital velocity. In the coupled calculation, the physical quantities are exchanged between the models as indicated by the arrows.

The three core models can be briefly described as follows. The WRF is a non-hydrostatic model that research institutions in the United States NCAR, NCEP, NOAA/FSL, AFWA has jointly developed. The ROMS is a quasi-three-dimensional ocean model and the governing primitive equations. The SWAN is a third-generation wave model using a spectral method that corresponds from deep water to shallow water.

\section{Physical conditions and input data}

A series of numerical simulations of typhoon Melor in 2009 was carried out around Tanabe bay, Wakayama Prefecture in Japan. The calculation by WRF was conducted down-scaling from the meso scale, $1000 \mathrm{~km}$ scale, with one-way nesting in order to reproduce in detail the distribution of typhoon wind speed around eye. The calculation period was set from September 23 to October 11, 2009, including the spin-up of computation about one week before typhoon landfall.

Fig. 2 shows a computational domain, and Table 1 shows the computational conditions and input data. The geometrical configuration of WRF was 40 vertical layers and the value of $\eta$ that is vertical sigma coordinate of WRF is taken tightly near surface because of the detail calculation near sea surface (Lower $\eta$ : 1.000, 0.999, 0.997, 0.994, 0.990, 0.985, 0.978, 0.969, 0.956, 0.939, 0.918, $0.894,0.870,0.845)$. Physics options in the atmosphere model are selected the models that matches the grid resolution. GTOPO 30 of USGS is used for elevation and land use data. Since GTOPO 30 is several $\mathrm{km}$ resolution data, therefore, digital elevation map data with the resolution of 50 $m$ by the Japanese Geographical Survey Institute was used for domain 3 (finest domain). Data assimilation for WRF was only applied to the domain 1.

The ROMS model was computed with 20 layers in vertical and with horizontal resolution of 12.5 $\mathrm{km}$ (domain 1) and $100 \mathrm{~m}$ (domain 3). Time steps of each model were given empirically to avoid the computational instability. The boundary condition of ROMS is mainly radiation condition but tidal elevation was overlapped at the lateral boundary. The SWAN model was calculated using the same domain size and grid resolution as ROMS. The basic configuration of SWAN was examined for wind energy input, wave interactions and wave energy dissipation.

These three models exchange the physical quantities every 600 seconds through the MIPCH interface.

\section{Coupling condition}

In order to analyze coupling effects, the calculations were carried out by changing the combination WRF (A), ROMS (O) and SWAN (W), respectively. For example, the full coupling between WRF, ROMS and SWAN denotes AOW. By following same manner, the coupling between ROMS and SWAN denotes OW and the single run of ROMS denotes $\mathrm{O}$ hereafter for simplicity. In addition, the bulk formula of momentum flux at the air-sea surface is one of important factor of coupled model. The Charnock formula was used to determine the roughness from friction velocity in case 


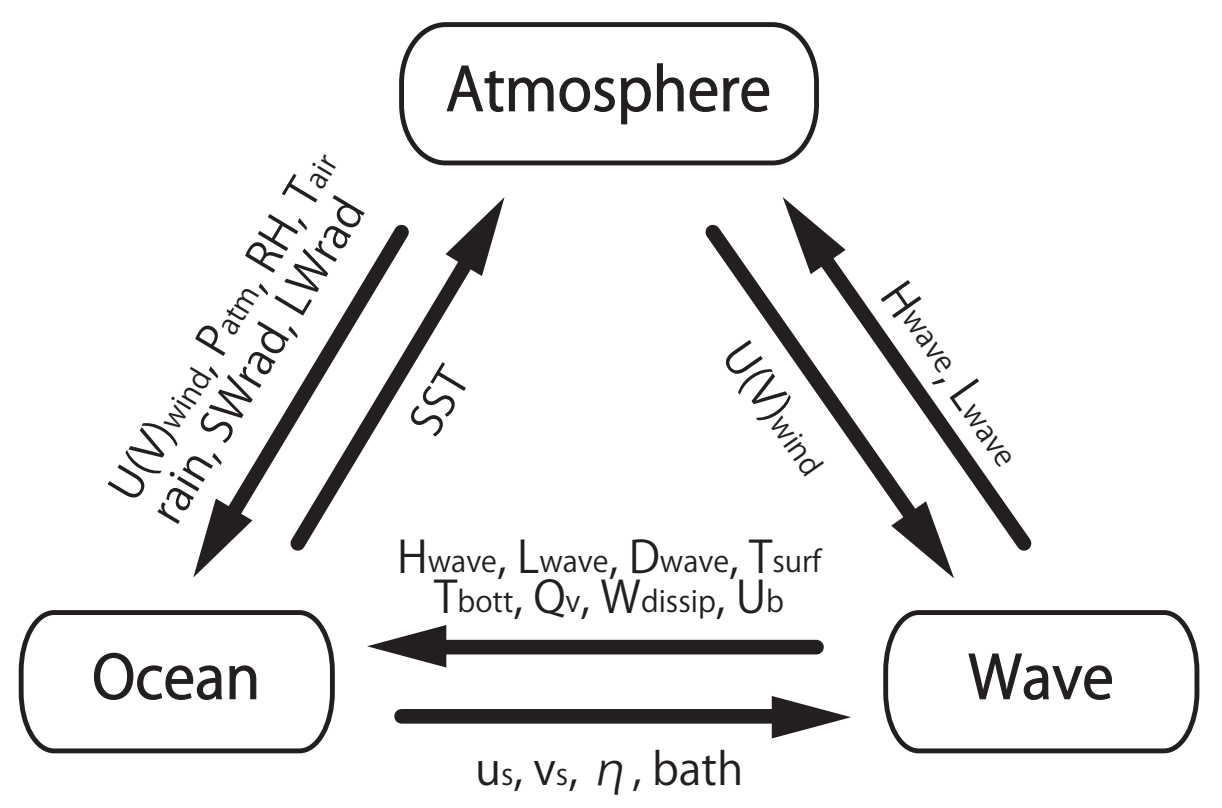

Figure 1. Diagram of COAWST (Coupled Ocean Atmosphere Wave Sediment Transport Modeling System)

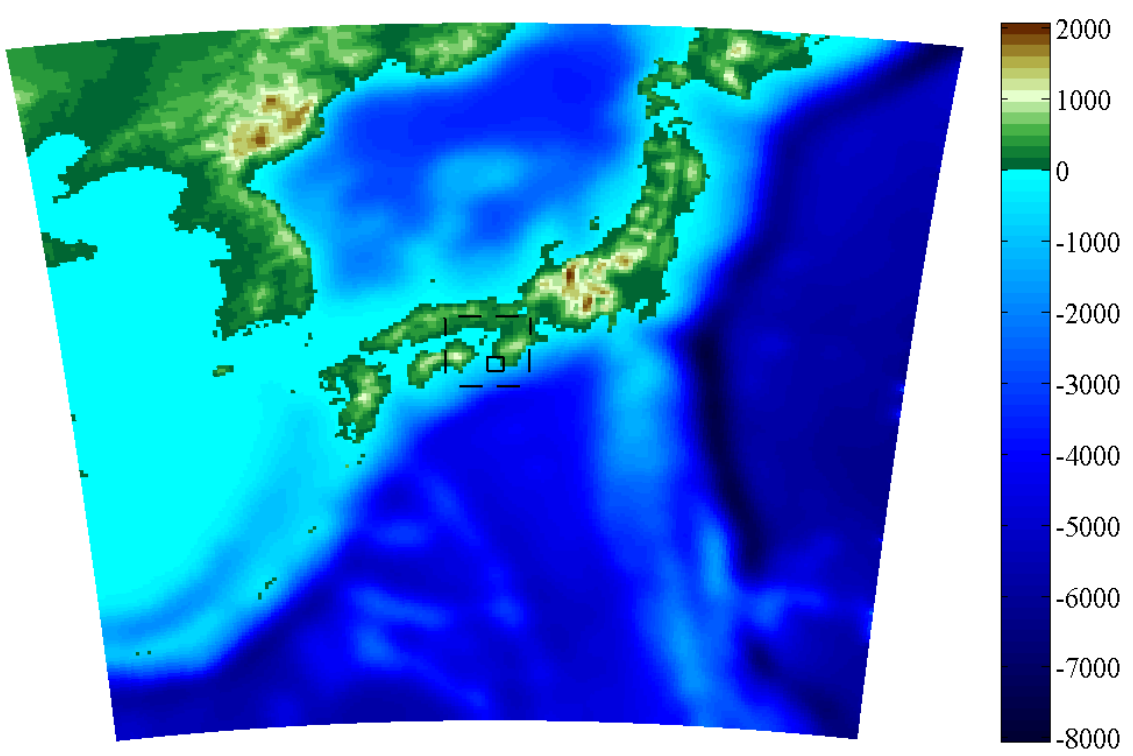

Figure 2. Computation domain (contour: elevation; dashed line: domain 2; solid line: domain 3) 
Table 1. Computational condition and input data

\begin{tabular}{|c|c|c|}
\hline \multirow[t]{15}{*}{ WRF } & Horizontal grid & $\begin{array}{l}\text { domain 1: } 300 \times 300(12.5 \mathrm{~km}) \\
\text { domain 2: } 100 \times 100(2.5 \mathrm{~km}) \\
\text { domain 3: } 100 \times 100(500 \mathrm{~m})\end{array}$ \\
\hline & Vertical layers & 40 \\
\hline & $\mathrm{dt}$ & $\begin{array}{l}\text { domain1:50 s, domain2:10 } \mathrm{s} \\
\text { domain3:2 s }\end{array}$ \\
\hline & Micro-physics & WSM 6-class graupel \\
\hline & Shortwave radiation & Dudhia \\
\hline & Longwave radiation & RRTM \\
\hline & Surface layer & Monin-Obukhov (Janjic Eta) \\
\hline & PBL & Mellor-Yamada-Janjic (Eta) TKE \\
\hline & Land surface & Unified Noah land-surface model \\
\hline & Cumulus & Kain-Fritsch (New Eta) \\
\hline & Urban model & $\mathrm{n} / \mathrm{a}$ \\
\hline & $\begin{array}{l}\text { Initial and } \\
\text { boundary condition }\end{array}$ & NCEP FNL \\
\hline & Elevation and & USGS GTOPO30 \\
\hline & $\begin{array}{l}\text { Landuse } \\
\text { Data assimilation }\end{array}$ & $\begin{array}{l}\text { Fundamental Geospatial Data (Japanese GSI) } \\
\text { domain1 }\end{array}$ \\
\hline & nesting & One-way \\
\hline \multirow[t]{7}{*}{ ROMS } & Horizontal grid & $\begin{array}{l}\text { domain 1: } 300 \times 300(12.5 \mathrm{~km}) \\
\text { domain 3: } 200 \times 200(100 \mathrm{~m})\end{array}$ \\
\hline & Vertical layers & 20 \\
\hline & $\mathrm{dt}$ & $\begin{array}{l}\text { domain 1: } 60 \mathrm{~s} \\
\text { domain 3: } 10 \mathrm{~s}\end{array}$ \\
\hline & Initial condition & Uniform \\
\hline & Boundary condition & TPXO 7.2 \\
\hline & DEM & GEBCO \\
\hline & nesting & $\mathrm{n} / \mathrm{a}$ \\
\hline \multirow[t]{4}{*}{ SWAN } & Horizontal grid & $\begin{array}{l}\text { domain 1: } 300 \times 300(12.5 \mathrm{~km}) \\
\text { domain 3: } 200 \times 200(100 \mathrm{~m})\end{array}$ \\
\hline & Direction & 36 \\
\hline & Frequency & $24(0.05-0.5 \mathrm{~Hz})$ \\
\hline & $\mathrm{dt}$ & $\begin{array}{l}\text { domain 1: } 300 \mathrm{~s} \\
\text { domain 3: } 120 \mathrm{~s}\end{array}$ \\
\hline Coupling & Interval & $600 \mathrm{~s}$ \\
\hline
\end{tabular}




\section{COASTAL ENGINEERING 2012}

of without wave model like case $\mathrm{O}$ or $\mathrm{AO}$. The Charnock formula is evaluated $z_{0}$ as a function of $u_{*}$ as

$$
z_{0}=\alpha_{C H} u_{*}^{2} / g,
$$

where $z_{0}$ is the roughness at sea surface, $u_{*}$ is the friction velocity and $g$ is the acceleration due to gravity. For the coupled model, alternative bulk flux model can be used based on wave information. Taylor-Yelland formula which uses significant wave height and wave steepness was used to determine the roughness in case of with wave model like case OW or AOW.

$$
\frac{z_{0}}{H_{s}}=A\left(\frac{H_{s}}{L_{p}}\right)^{B}
$$

where $H_{s}$ is the significant wave height, $L_{p}$ the wavelength at the peak frequency, and $A(=1200)$ and $B(=4.5)$ the empirical constants.

\section{RESULTS AND DISCUSSION}

This chapter summarizes the results of numerical experiments against (1) the validation of the atmosphere model that is the input for the ocean and wave model, (2) the comparison of currents and waves between the observation and the computations in mesoscale, and (3) the comparison of spatial and temporal series at the Shirahama observation tower, respectively. In the following section, figures of mesoscale are the results of domain 1 (largest domain) and figures of the results at Shirahama observation tower is the results of domain 3 (finest domain).

\section{Validation of the atmosphere model}

Fig. 3 shows the analysis tracks of typhoon path, the best track data, in every 6 hours by of Japan Meteorological Agency (JMA) and the numerical results. The red solid line with a circle shows the best track data, blue dotted line with * is Case A, light blue dashed line with $\mathrm{x}$ is Case $\mathrm{AO}$, pink dashed line with + is Case AOW, respectively. The numerical results are the point to be the minimum value of the pressure at sea level. Although each case seems to be a good agreement with TC best track but there is a time lag in passing through the same point just before TC landfall because of the slightly slower translation speed of movement of typhoon by the model. Overall, it is considered that the typhoon track is well reproduced in all cases due to the effect of data assimilation.

Fig. 4 shows the time variations of the sea level pressure (SLP), wind velocity and wind direction at Shirahama observation tower. The black solid line is the observation result, blue dotted line is Case A, light blue dashed line is Case AO, pink chain line is Case AOW, respectively. Although the atmospheric pressure before and after the passing typhoon is estimated slightly higher (shallower), rapid decrease related with the closest approach of TC is reproduced well in all cases. The peak value of wind speed shows good agreement with each other, but the influence of the slow translation speed of the typhoon gives different time variation of the wind speed at fixed point. The large variations in wind direction can be observed before the TC land fall on October 6th which atmospheric condition is almost calm. This is due to sensitivity of wind field due to front and surrounding TC. However, the wind direction changes due to passing typhoon, which gives reasonable prediction by the model.

Fig. 5 shows the spatial distribution of wind speed above $10 \mathrm{~m}$ from land or sea at 19:00 on October 7th in Cases A and AOW, respectively. The contour indicates the wind speed, and vector the wind direction. As shown in Fig. 5, the major typhoon storm area is smaller by coupling the models. It can be considered that the typhoon weakened due to SST feedback by full the coupling atmosphere model. The wave induced disturbance and related SST change give negative impact to TC structure. In addition, this result is consistent with the result of Warner et al. (2010) comparing the time variation of the maximum wind speed of the hurricane. 


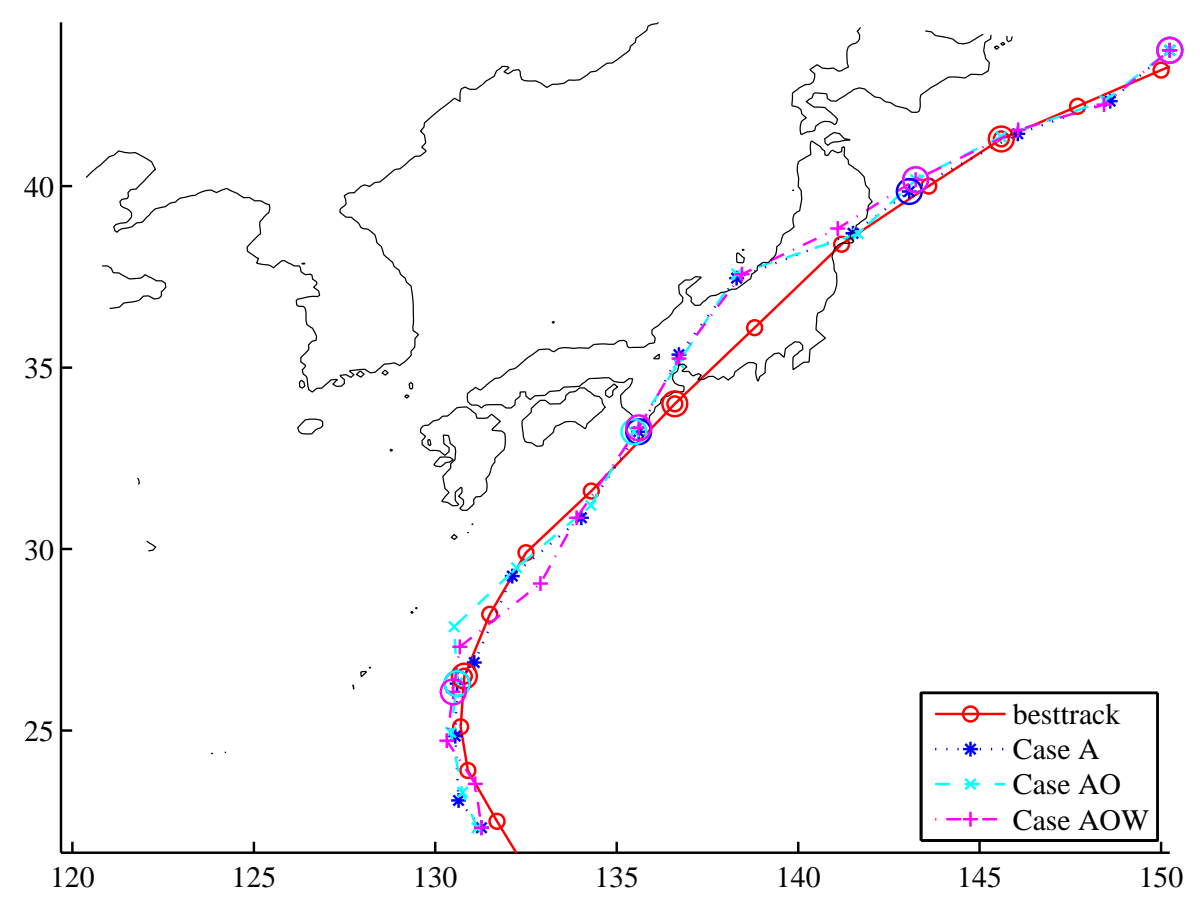

Figure 3. Tracks of typhoon path every 6 hours of best track by JMA and the calculated results (red solid line with a circle: the best track data by JMA; blue dotted line with *: case A; light blue dashed line with $x$ : case $A O$; pink dashed line with + : case AOW)

\section{Comparison between the results in mesoscale}

As shown in Fig. 5, the wave induced disturbance and related SST change give negative impact to TC structure. To discuss the coupling effects in detail, Fig. 6 shows the distribution of the ocean side turbulent kinetic energy (TKE) near the sea surface in 19:00, October 7, 2009. The spatial distribution of TKE is tended to increase due to receiving the energy from the wave dissipation by coupling wave model. On the other hand, in case of coupling the atmosphere model, the typhoon weakens and TKE decreases. The case $\mathrm{O}$, single run of ocean model, shows the smallest TKE magnitude among the experiments. On the other hand, the case OW shows the largest TKE due to neglection of atmosphere feedback. The case AOW, full coupling, shows intermediate results but spatial distribution of TKE is not uniformally distributed in comparison with other model. The both wave induced disturbance and atmosphere-ocean coupling are important to describe quantatitave and qualitative structure of TC.

\section{Comparison of the results at the Shirahama observation tower}

Fig. 7 and 8 show the time histories of water temperature and horizontal current velocity at Shirahama observation tower, respectively. All numerical results of the initial water temperature are underestimated by the $1{ }^{\circ} \mathrm{C}$ compared to observation. The target area partially includes Kuroshio effects and it gives complex structure of water temperature vertically. The difference is due to less accurate given lateral boundary condition for ROMS and it will be improved near future. The one of feature of observation results is rapid decrease of water temperature of about $1{ }^{\circ} \mathrm{C}$ and the generation of fast surface current during typhoon passing. The trend of decreasing 

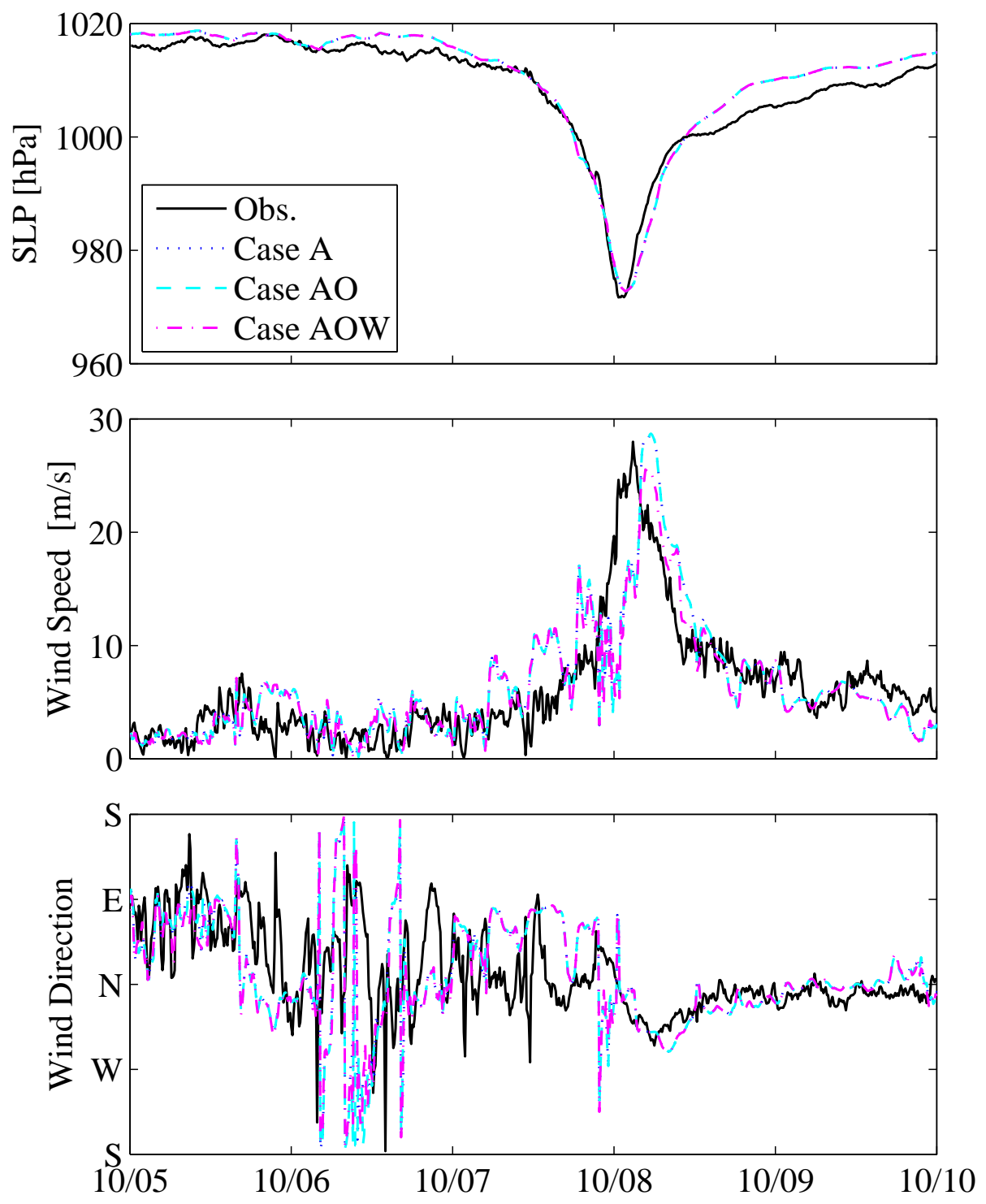

Figure 4. Time history of sea level pressure (SLP), wind velocity and wind direction at Shirahama observation tower (black solid line: observed data; blue dotted line: case $A$; light blue dashed line: case $A O$; pink chain line: case AOW)

water temperature before and after the passing typhoon is reproduced in case of coupling the atmosphere model (AO and AOW). The latent heat flux due to feedback to the atmosphere is 


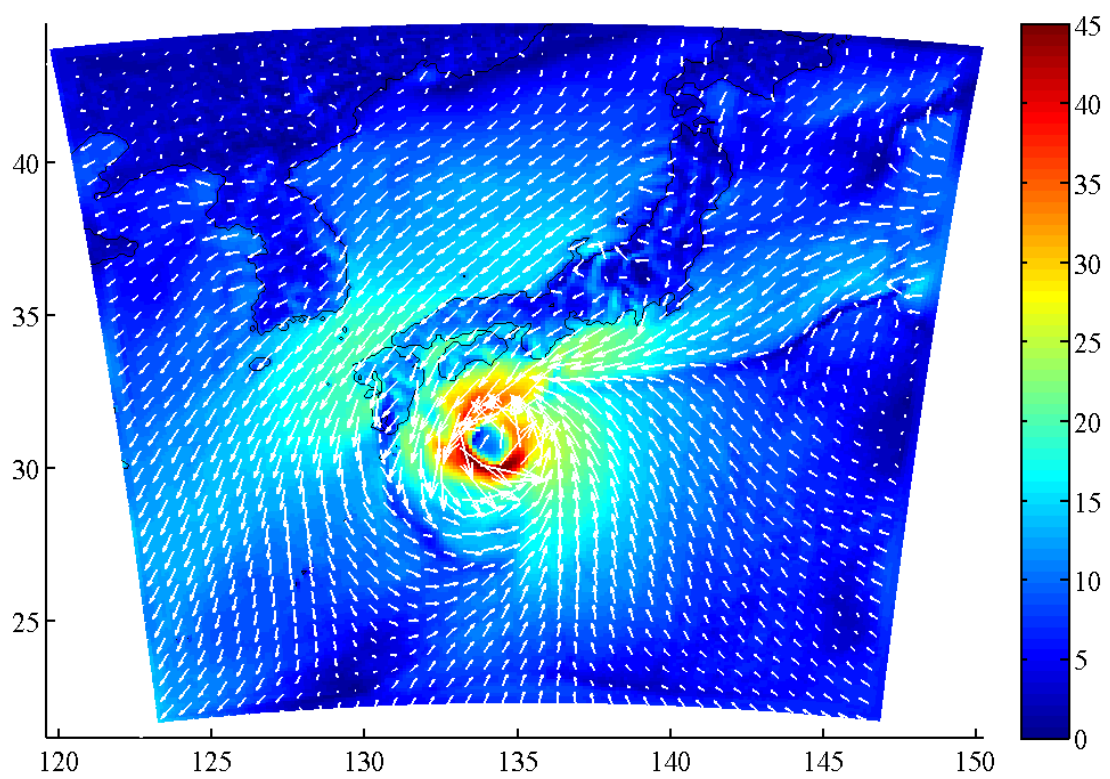

(a) Case A

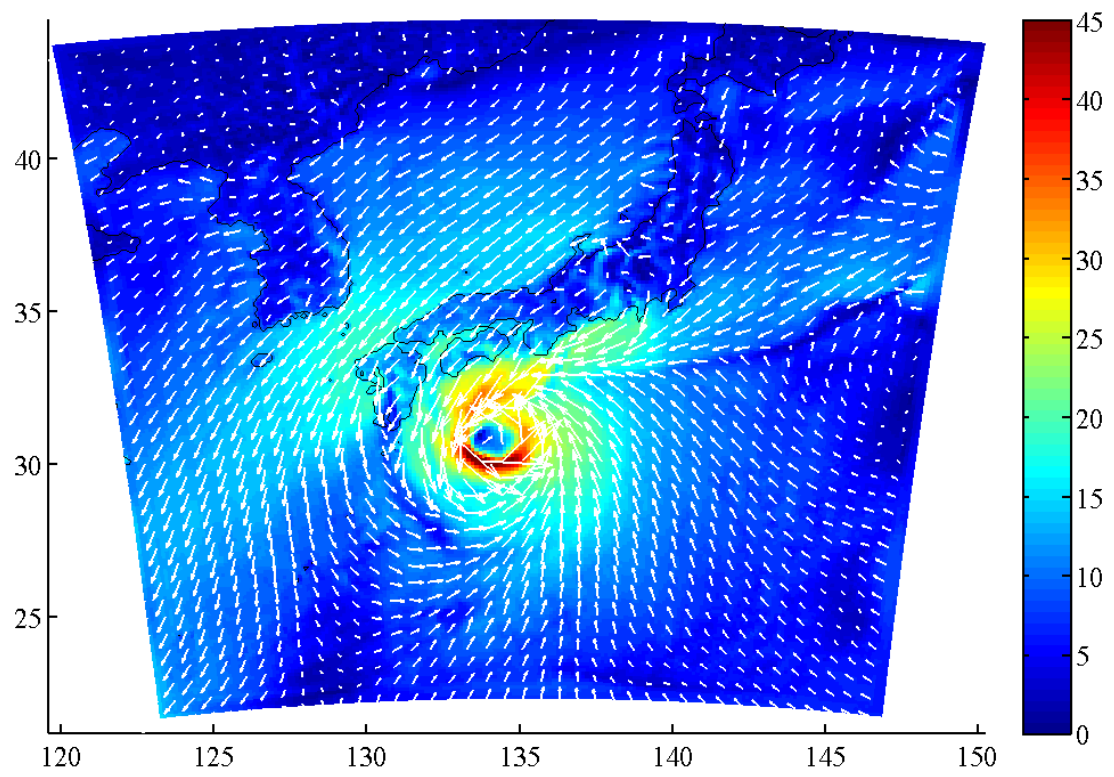

(b) Case AOW

Figure 5. Spatial distribution of wind speed above $10 \mathrm{~m}$ from land or sea at 19:00 on October 7th, 2009 (unit:[m/s]; contour: wind velocity; vector: wind direction) 


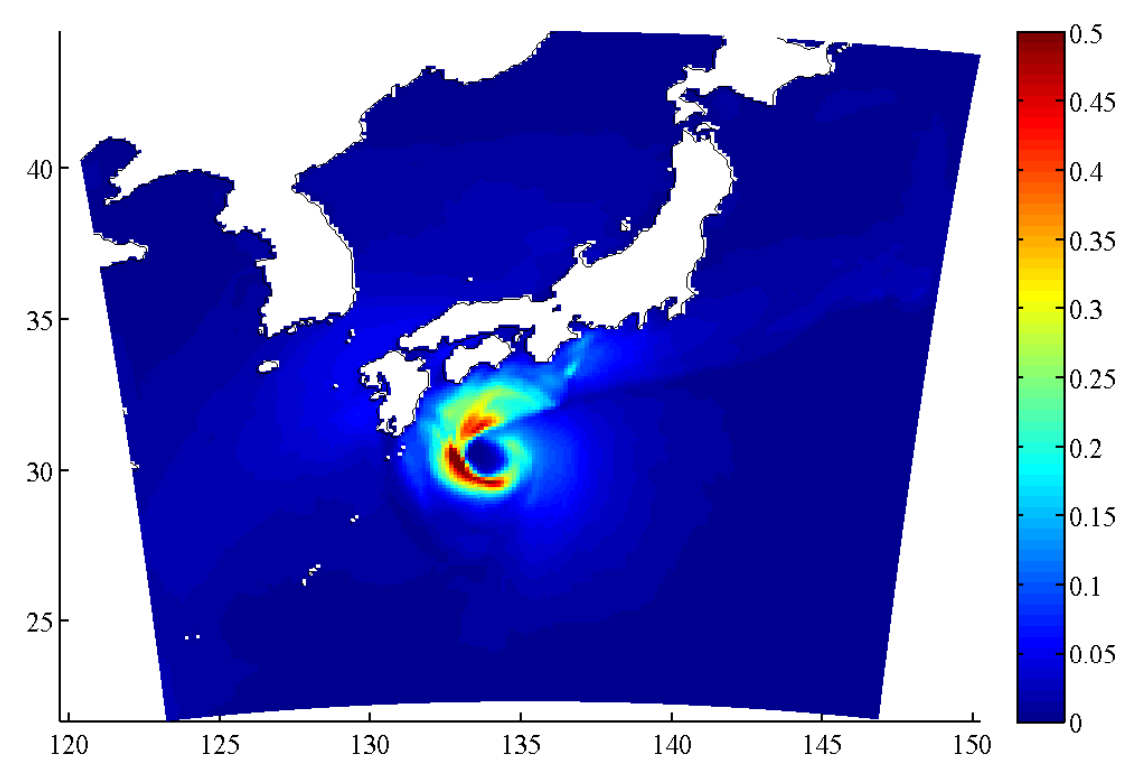

(a) Case O

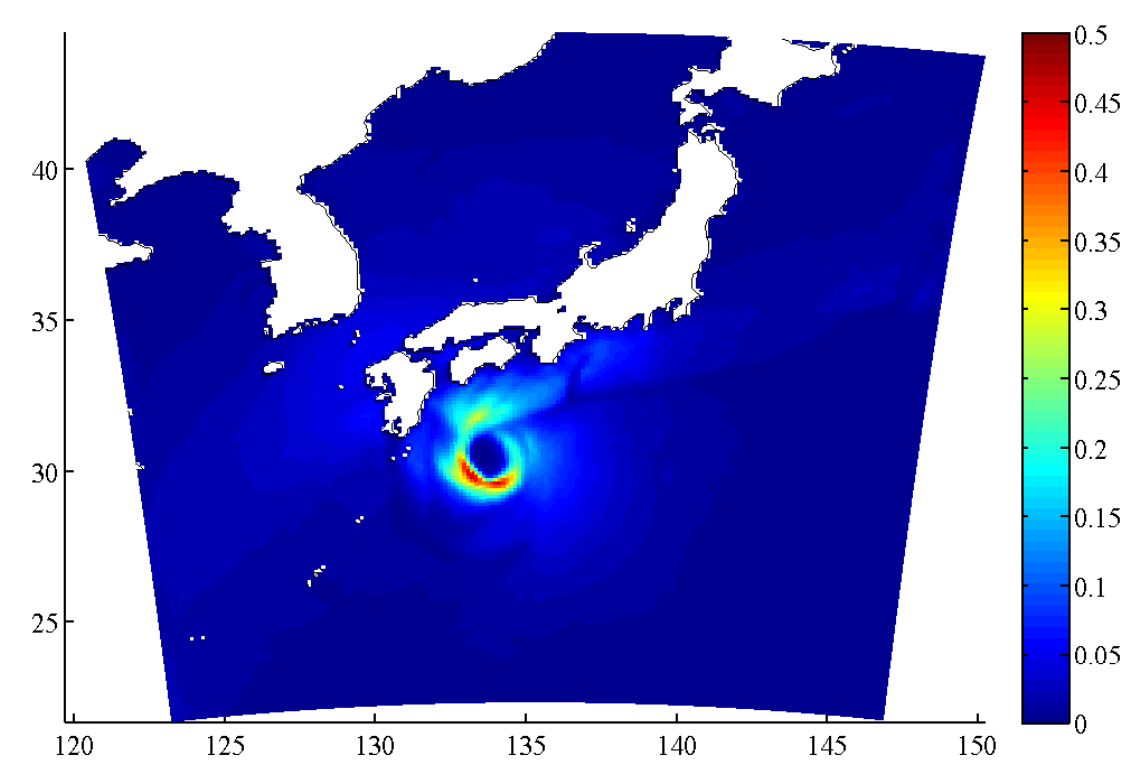

(b) Case AO

Figure 6. Spatial distribution of turbulent kinetic energy (TKE) near the sea surface in 19:00, October $7,2009\left[\mathrm{~m}^{2} / \mathrm{s}^{2}\right]$ 


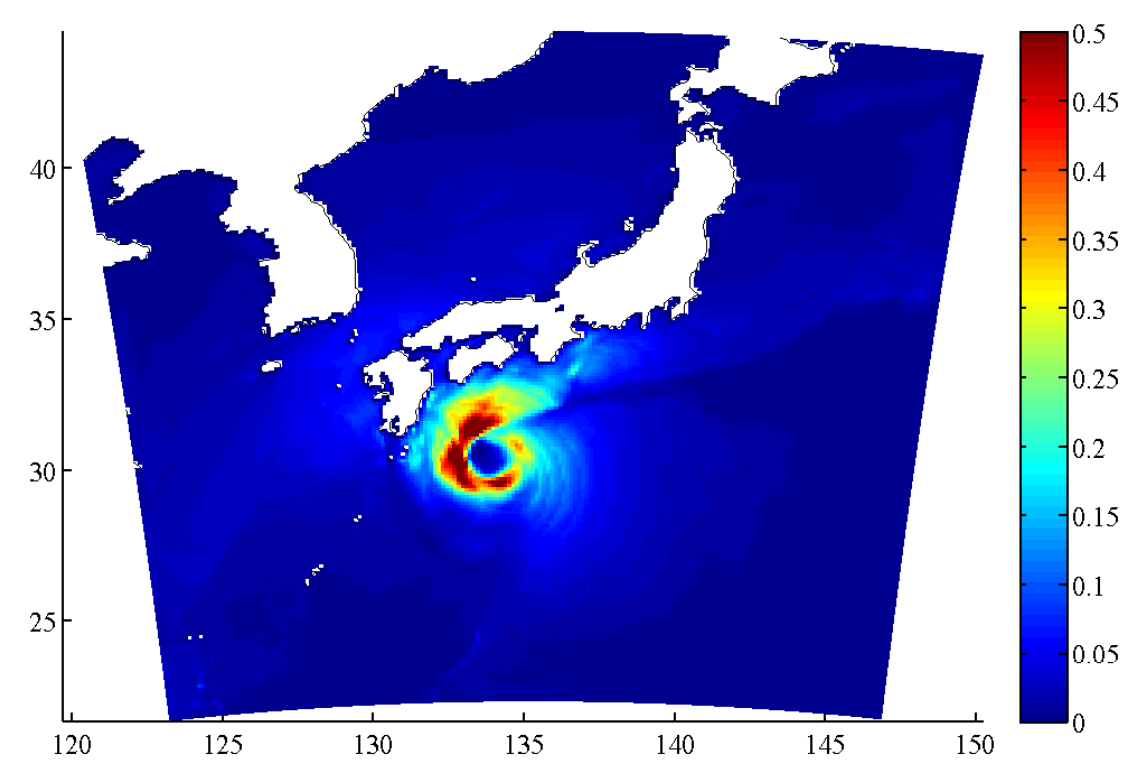

(c) Case OW

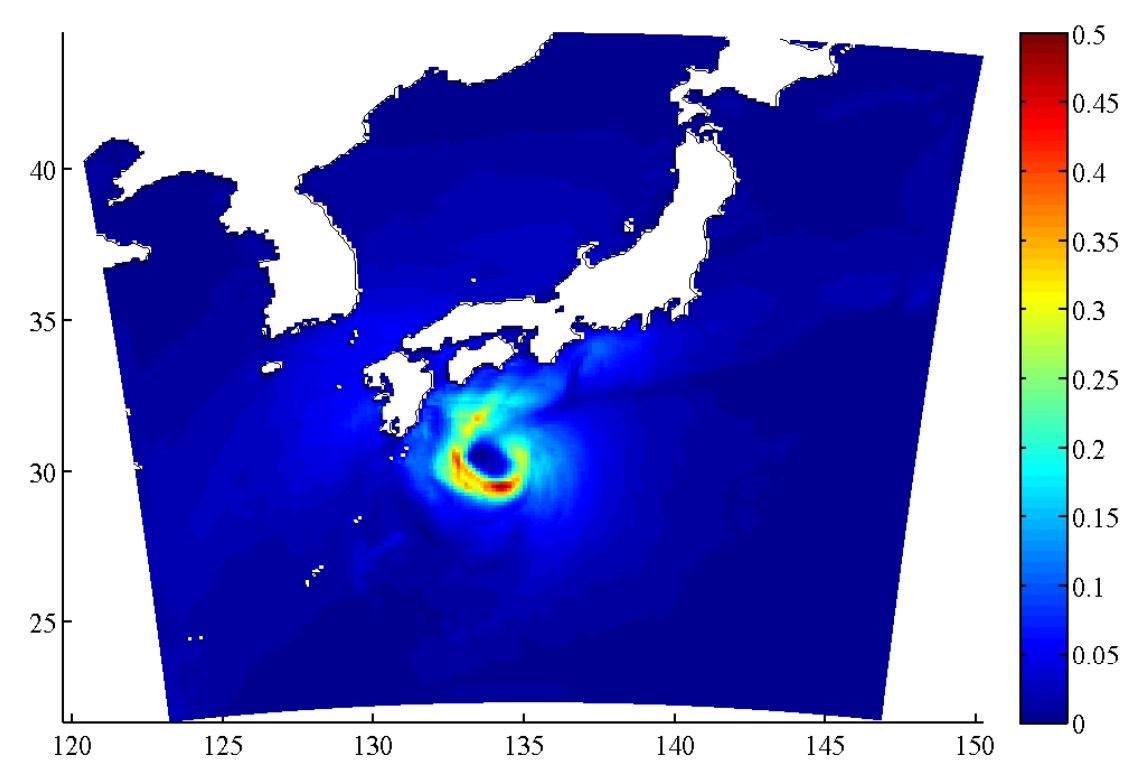

(d) Case AOW

Figure 6. Spatial distribution of turbulent kinetic energy (TKE) near the sea surface in 19:00, October 7, $2009\left[\mathrm{~m}^{2} / \mathrm{s}^{2}\right]$ (cont.) 


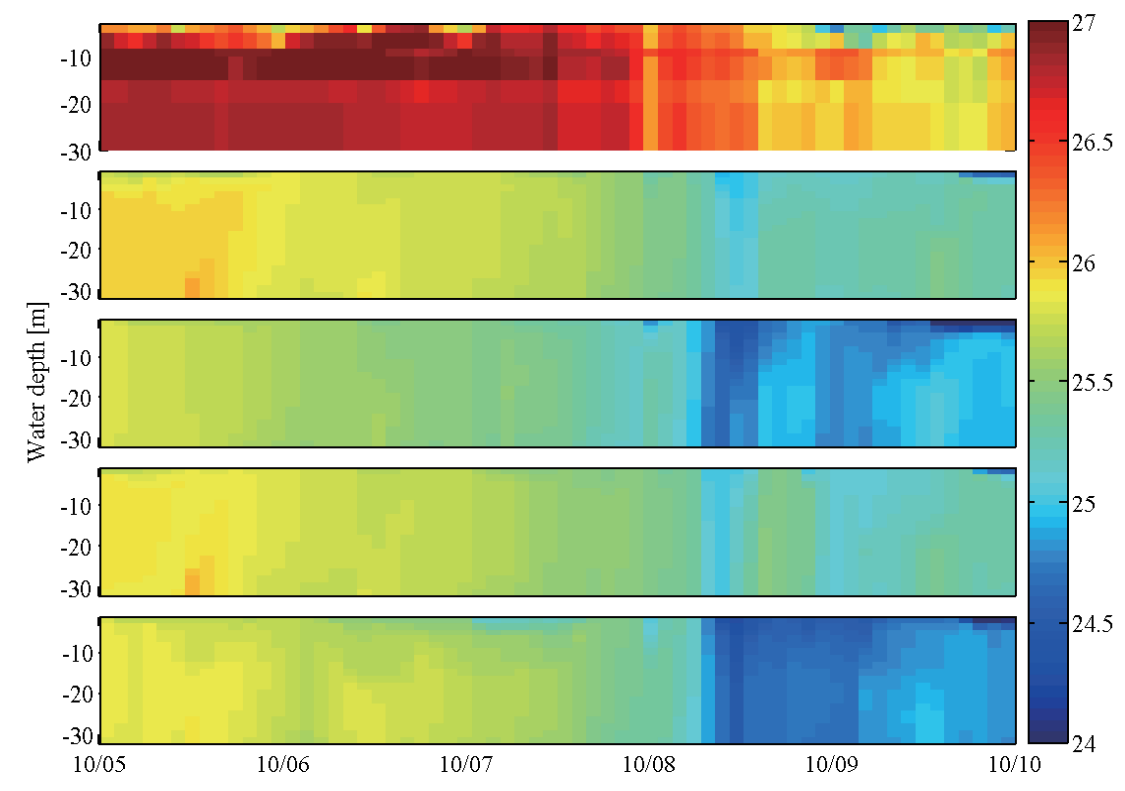

\section{Figure 7. Time variation of water temperature at Shirahama observation tower $\left[{ }^{\circ} \mathrm{C}\right]$ (observation, Case O, AO, OW, AOW from the top to bottom)}

effective for temperature change in the ocean, and the impact of wave is relative small for sea temperature distribution. On the other hand, the wave model gives effective impact to the current velocity distribution. The observation by ADCP ranged 0-6 m near sea surface was carried out mounted on the sea bottom, while the numerical results give whole the water depth of about $30 \mathrm{~m}$. The numerical results are overestimated in case of coupling the wave model, and appearance time of maximum current of more than $250 \mathrm{~mm} / \mathrm{s}$ is delayed in comparison with the observed data. This is due to wave coupling effect with parameterization problem in Eq.(2). A simple coupling between the models does not give better results, and it is necessary to replace the law of momentum flux that is suitable for the coupled model.

Before conclude this manuscript, we would point out the future improvement of wave model itself. Fig. 9 shows the time history of significant wave height and period at Shirahama observation tower location. The black solid line denotes the observed result, blue dashed line Case OW, pink chain line Case AOW, respectively. The main feature of observed wave height variation is the large swell 12 hours before the passing typhoon and the wind wave after that. The numerical results are not able to simulate the large swell before the passing typhoon. The peak wave height at the time of closest approach typhoon is able to be reproduced in all cases; however, wave height is overestimated when the swell is remaining like after the typhoon. As shown in previous figures, the surface mixing due to TC started 12 hours landfall and it is due to swell mixing and breaking nearshore. The accuracy of swell gives significant impact to nearshore temperature and current mixing under the TC condition and the improvement of swell propagation is highly desire for the coupling model. 


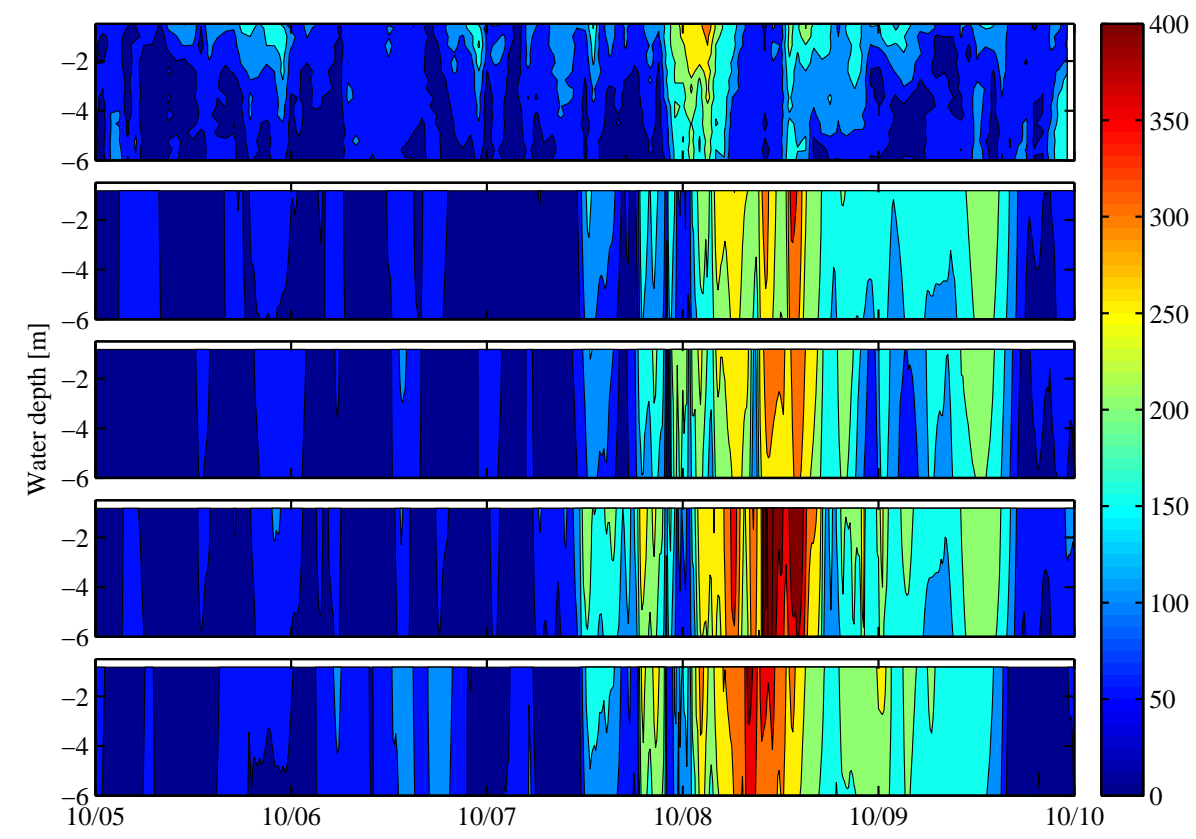

Figure 8. Time variation of horizontal current velocity at Shirahama observation tower $[\mathrm{mm} / \mathrm{s}]$ (observation, Case $\mathrm{O}, \mathrm{AO}, \mathrm{OW}, \mathrm{AOW}$ from the top to bottom)

\section{CONCLUSIONS}

The differences in the numerical results by changing the coupling conditions between the atmosphere, ocean and wave model were examined against targeting typhoon Melor in 2009. The numerical results respect to typhoon tracks, ocean current, ocean temperature and waves are summarized as follows.

- The typhoon track was reproduced well by all models, but there is a delay of translation around the coastal areas. Coupling of the atmosphere model and wave model reduced the area of the strong wind.

- The total kinematic energy of ocean side (TKE) near sea surface is increased due to coupling the wave model. On the other hand, the TKE is decreased due to coupling with atmosphere model and it gives weaker typhoon.

- The feedback of sensitive and latent heat by coupling the atmosphere model and ocean model is effective for the water temperature change by the passing typhoon. The dissipation of wave energy by the wave model is effective for the current change.

There are many choice of bulk formula for momentum and heat flux at the sea surface if the atmosphere-ocean-wave coupling is used for modeling. There is not well validated bulk formula including wave information and future validation is necessary for the fully coupled model.

\section{REFERENCES}

Booij, N., R. Ris, and L. Holthuijsen. 1999. A third-generation wave model for coastal regions. imodel description and validation, Journal of geophysical research, 104(C4), 7649-7666. 

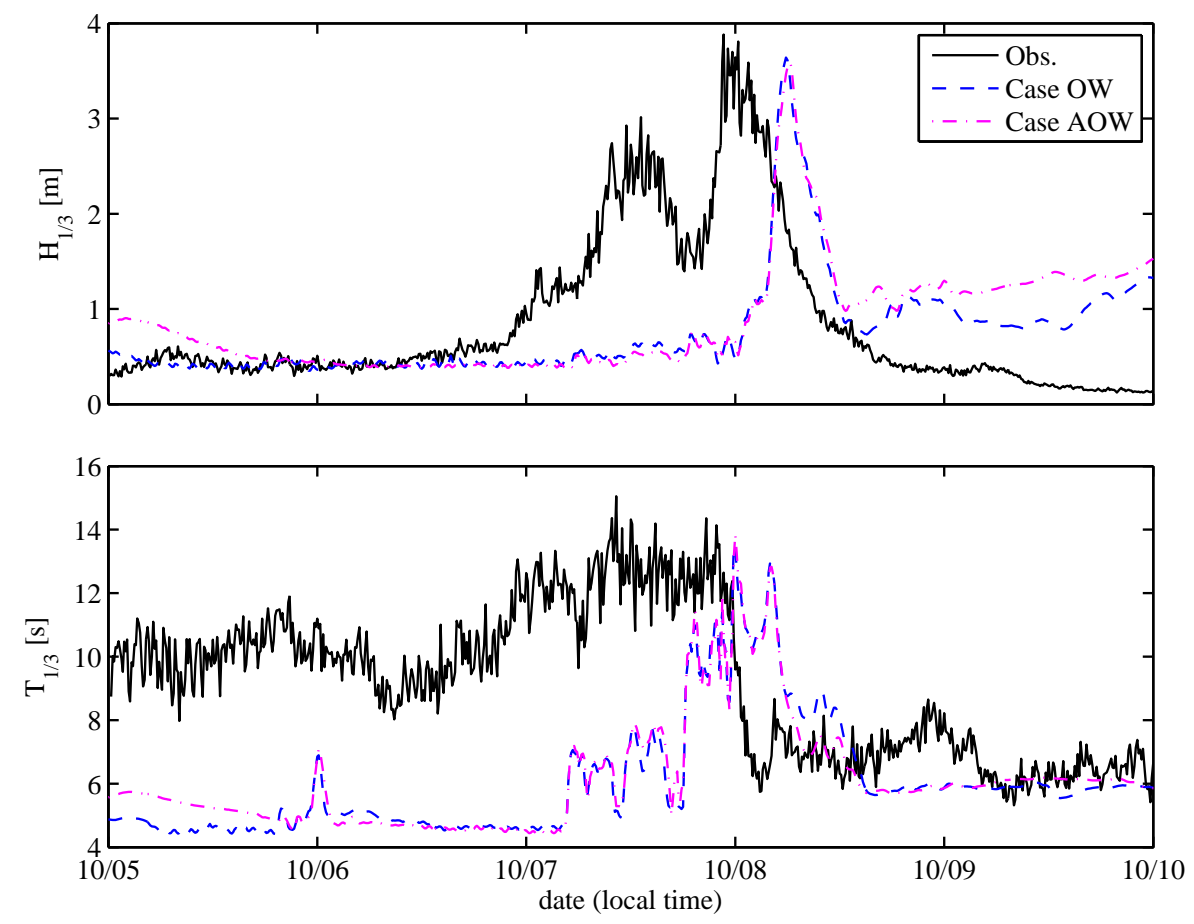

Figure 9. The time variation of significant wave height and period at Shirahama observation tower (Black solid line: observed result, blue dashed line: case OW, pink chain line: case AOW)

Mori, N., T. Suzuki, and N. Kihara. 2010. A study on air-sea mixing due to wind and wave under strong wind condition, Journal of JSCE, Ser. B2 (Coastal Engineering), 66(1), 311-315.

Murakami, T., T. Yasuda, and T. Ohsawa. 2004. Development of a multi-sigma coordinate model coupled with an atmospheric model for the calculation of coastal currents, Annual Journal of Coastal Engineering, 51(1), 366-370.

Shchepetkin, A. and J. McWilliams. 2005. The regional oceanic modeling system (roms): a splitexplicit, free-surface, topography-following-coordinate oceanic model, Ocean Modelling, 9(4), $347-404$.

Skamarock, W., J. Klemp, J. Dudhia, D. Gill, and D. Barker. 2005. A description of the advanced research wrf version 2, NCAR Tech. Note NCAR/TN-468+STR,.

Soo, L. H., T. Yamashita, T. Komaguchi, and T. Mishima. 2009. Reanalysis of typhoon meteorological fields and related waves and surges in the seto inland sea, Journal of JSCE, Ser. B2 (Coastal Engineering), 65(1), 441-445.

Warner, J., B. Armstrong, R. He, and J. Zambon. 2010. Development of a coupled oceanatmosphere-wave-sediment transport (coawst) modeling system, Ocean modelling, 35(3), 230244. 


\section{COASTAL ENGINEERING 2012}

Warner, J., C. Sherwood, R. Signell, C. Harris, and H. Arango. 2008. Development of a threedimensional, regional, coupled wave, current, and sediment-transport model, Computers 83 Geosciences, 34(10), 1284-1306.

Yamashita, T., K. Kim, H. Lee, and H. Mohhamed. 2007. Environment simulator: Contribution to coastal engineering problems, Annual Journal of Coastal Engineering, 54(2), 1301-1305.

Yoshino, J., K. Kobayashi, H. Kojima, and T. Yasuda. 2009. Estimation of potential storm surge and wave heights in the bag of ise based on the atmosphere and ocean dynamics, Journal of JSCE, Ser. B2 (Coastal Engineering), 65(1), 396-400. 